\title{
The Relationship Between Health Literacy Level and Self-Care Behaviors in Patients with Diabetes
}

This article was published in the following Dove Press journal:

Patient Related Outcome Measures

\author{
Davood RobatSarpooshi' \\ Mehrsadat Mahdizadeh ${ }^{2}$ \\ Hadi Alizadeh Siuki ${ }^{3}$ \\ Mohammad Haddadi ${ }^{4}$ \\ Hamid Robatsarpooshi ${ }^{5}$ \\ Nooshin Peyman ${ }^{2}$ \\ 'Department of Health Education and \\ Health Promotion, Student Research \\ Committee, Social Determinants of \\ Health Research Center, Faculty of \\ Health, Mashhad University of Medical \\ Sciences, Masshad, Iran; ${ }^{2}$ Department of \\ Health Education and Health Promotion, \\ Social Determinants of Health Research \\ Center, Faculty of Health, Mashhad \\ University of Medical Sciences, Mashhad, \\ Iran; ${ }^{3}$ Department of Public Health, \\ Torbat Heydariyeh University of Medical \\ Sciences, Torbat Heydariyeh, Iran; \\ ${ }^{4}$ Department of Nursing and Midwifery, \\ Sabzevar University of Medical Sciences, \\ Sabzevar, Iran; ${ }^{5}$ Department of Nursing, \\ Tabas Branch Islamic Azad University, \\ Tabas, Iran
}

Background: The most important factor in controlling diabetes is self-care behaviors; improving self-care behaviors is the first step in helping patients to better control and manage their diseases and health literacy is recognized as a vital and important indicator of outcomes and costs in healthcare. Therefore, the effectiveness of health-care systems requires that people have the desirable health literacy level. Therefore, this research intended to study the relationship between health literacy levels in patients with diabetes and their self-care behaviors.

Patients and Methods: This analytical cross-sectional study was conducted during two months on 400 patients with diabetes selected using the census method in diabetes clinics in Mashhad County. Information was collected through a demographic survey questionnaire, the Health Literacy Questionnaire and a self-care behavior questionnaire. Data analysis was performed using SPSS 21 and Spearman correlation coefficient, the independent $t$-test, and ANOVA.

Results: The total mean score for self-care was 33.52 ( $\mathrm{SD} \pm 13.27$ ). There was a significant relationship between self-care and health literacy in this study $(\mathrm{P}<0.05)$ so that people with higher levels of self-care literacy had better self-care behaviors. There was also a significant relationship between education level and monthly income and self-care behaviors and health literacy $(\mathrm{P}<0.001)$.

Conclusion: Patients received an average score for self-care behaviors. Given the impact of health literacy on patients' self-care behaviors, and considering its inclusion in educational, therapeutic, and caregiver programs, it is possible to reduce complications in patients, and improve their quality of life, by improving their self-care behaviors. Special attention should also be paid to health literacy levels of the audience when designing the related educational programs.

Keywords: health literacy, diabetes, self-care

\section{Introduction}

Chronic diseases including diabetes have complex origins, slow onset, unpredictable deterioration, and improvement and require self-care due to their long process. ${ }^{1}$ Diabetes, especially type 2 diabetes, is one of the major threats to human health in the twenty-first century and one of the global problems and the main causes of death and disability. ${ }^{2}$

There are now more than 380 million diabetes patients in the world. ${ }^{3}$ In Iran, 7.7 percent of the population suffers from diabetes, which imposes very high costs on the health care system. It is estimated that the annual cost of treating diabetes in the world is more than 174 billion\$. ${ }^{4}$ In Iran, according to statistics published by the General
Correspondence: Nooshin Peyman Department of Health Promotion and Education, Faculty of Health, Mashhad University of Medical Sciences, Mashhad, Iran

Tel +985138544643

Fax +985138517505

Email nooshin.peyman@yandex.com 
Directorate of Disease Prevention and Control, and based on the Iranian Ministry of Health tariffs, the direct annual cost of diabetes is about 123 milliard Tomans $(8.5$ million $\$){ }^{4}$ One of the main direct costs of this disease is that of hospitalization for treating the chronic complications of this disease. ${ }^{5}$

Uncontrolled diabetes often results in complications such as heart disease, stroke, hypertension, blindness, kidney disease and amputations. ${ }^{6}$ The developing countries will bear a greater share of diabetes patients (1). As one of the countries in the Middle East, Iran is also affected by this problem. ${ }^{7}$ The national study on risk factors of noncommunicable diseases predicted and there will be more than 6 million patients with diabetes in $2030 .^{8}$

Diabetes self-care is one of the most important and basic strategies for controlling it and can prevent $85 \%$ of the problems caused by this disease in addition to reducing re-hospitalization of diabetes patients. ${ }^{9}$

In a study conducted by Reisi et al, about 46.5, 38 and $15.5 \%$ of the adult diabetes patients had adequate, borderline and inadequate health literacy levels, respectively. ${ }^{11}$ Similar studies also showed that low health literacy levels reduced the participation of patients with diabetes in educational programs held by health treatment centers. Consequently, they cannot benefit from the services that are provided through these programs, adopt timely and preventive self-care behaviors and avoid delays in the timely diagnosis of the disease and increased mortality and disability caused by chronic diseases.

Studies have shown that inadequate health literacy levels in individuals lead to less adherence to guidelines on health, increased incidence of hospitalization and organ failure in chronic diseases caused by noncompliance with guidelines for prevention. ${ }^{11}$ The International Association of Healthcare Professionals has divided health literacy dimensions into the four groups of health information acquisition, understanding, evaluation, and analysis and use. Most health education and information systems are designed to use written material (pamphlets, posters, and educational booklets) that require sufficient reading, evaluating and decision-making skills in the users, whereas the majority of adults lack sufficient skills in these areas, which makes the educational programs inefficient. Despite the importance of health literacy in prevention and self-care, many physicians and health professionals do not have sufficient confidence in health literacy, and most educational programs are implemented without attention to the importance of health literacy dimensions in learning and adhering to health guidelines.
Improving self-care behaviors is the first step in helping patients better control their illness, highlights the importance of understanding the factors that influence selfcare behaviors in diabetes patients and requires designing and strengthening interventions related to self-care behaviors. Also, it helps caregivers to better treat the disease and reduce its complications. ${ }^{12}$ Limited health literacy levels harm health knowledge, preventive behaviors and the ability to follow health care programs. ${ }^{13}$ Therefore, this study aimed at investigating the relationship between health literacy and self-care behaviors in these patients to reduce diabetes complications, improve quality of life in patients with this disease and decrease the economic load of diabetes on the family and society through strengthening this relationship.

\section{Patients and Methods}

In this cross-sectional analytic study, all 400 diabetic patients with inclusion criteria were selected from patients referred to health centers and private and public diabetes clinics in Mashhad. The purpose of the study was to complete the questionnaires to participating in the study. The sampling method was available through Convenience Sampling so that the sample population was selected simply because of its simplicity and availability. That is all referrals to diabetes clinics and health centers that had diabetes and were eligible to enter the study upon completion of the written consent form They were included in the study. The researcher visited the research environments and entered the patients into the research after introducing himself, explaining the title and purpose of the research to the patients and receiving written informed consent from them.

Inclusion criteria included the willingness to participate in the study, definitive diagnosis of type 2 diabetes based on laboratory documents found in the patients' health records at health treatment centers, lack of chronic illnesses and diabetes complications, age 30 and over, Iranian nationality, and at least a six-month history of diabetes. Exclusion criteria included a decision to leave the study, complications of diabetes, gestational diabetes and any medical problems that prevented self-care behaviors (such as exercise and regular physical activity).

The instrument used in this study consisted of two parts: demographic characteristics (11 questions) and the Summary of Self-Care Behaviors Activity Questionnaire introduced by Tolbert et al and cited by Lin et $\mathrm{al}^{14}$ whose validity and reliability have been proven in many studies 
in Iran including the research by Hatamloo et al. ${ }^{15}$ This questionnaire consists of 12 questions and measures selfcare behavior in four domains (diet, physical activity, selfmonitoring of blood sugar and antidiabetic drug use) over the past 2 days.

In this questionnaire, scores given to items ranged from zero to two. The patient received the highest score $^{2}$ by answering a question such as "How many days of exercise or physical activity did you have in the past week?" with "every single day of the week," and received the score of zero if the answer was "not on any day of the week." This was done for all four domains of self-care behaviors (diet, physical activity or exercise, antidiabetic drug use, and selfmonitoring of blood sugar). Higher scores indicate more desirable adherence to self-care behaviors in the past week. It should be noted that the researcher completed the questionnaires Data collection tools also included the questionnaire Health Literacy for Iranian Adults (HELIA) designed by Montazeri et al in 2014. They determined its validity and reliability. It consists of two parts: Part A, demographic characteristics of the respondents with 6 questions and Part B, 29 items in 5 domains including access (6 items), reading skills (4 items), understanding ( 7 items), and evaluation and decision making (12 items). It was scored on a 5-point Likert scale, and the total score ranged from one to 165 . Higher scores indicated higher health literacy levels, and the patients' levels of health literacy were categorized into the three classes of good, fair and poor according to the scores given for the five domains. ${ }^{16}$

Data were analyzed by SPSS 21 and through employing descriptive statistics (mean, standard deviation, frequency) and Pearson parametric test, the independent $t$-test and one-way ANOVA.

\section{Results}

The mean age of the participants was $53.8 \pm 11.9$ (range 33-71). The majority of the participants (89\%) had type 2 diabetes, $59 \%$ were female, $69 \%$ were married, $35 \%$ had average education level, most of them (68\%) regularly visited their physicians and $73 \%$ had a family history of diabetes. Physicians and clinic personnel were the sources of health information on diabetes for $76 \%$ of the patients.

Comparison of the means of self-care scores based on individual characteristics of patients and disease features did not show any significant differences between the various age-groups in mean scores of self-care behaviors $(\mathrm{P}=\mathrm{NS})$.
The results showed that there were significant relationships between the mean scores of self-care and education levels, economic status and regular visits to physician so that the mean scores of self-care were significantly higher in patients with university education and excellent economic status and in those who paid regular visits to their physician compared to other patients (Table 1).

There was no significant relationship between gender, marital status and family history of the disease and selfcare behaviors in the studied population ( $\mathrm{P}=\mathrm{NS}$ ).

In descriptive statistics, the total mean score for selfcare was $33.52(\mathrm{SD}=13.27)$. Based on the selected desirability level, it indicated that patients received an average score for self-care behaviors. Moreover, a comparison of the mean self-care scores for the various dimensions indicated that the highest averages were those of the diet and blood glucose monitoring dimensions and the lowest those of the physical activity the proper drug use dimensions (Table 2).

In the present study, the mean health literacy status in the patients in the different dimensions of health literacy showed that the participants had higher scores in the decision making and behavior dimension compared to the other dimensions (Table 3).

Pearson correlation coefficient (Table 4) revealed that there were significant relationships between the various dimensions of health literacy (reading, access, understanding, evaluation, use, and decision making) and the domains of self-care behavior (healthy eating, physical activity, blood glucose monitoring, proper consumption of medications) $(\mathrm{P}<0.05)$.

\section{Discussion}

The purpose of this study was to investigate the relationship between health literacy and self-care behaviors in patients with diabetes admitted to public and private centers in Mashhad.

The mean score of self-care was $34.85 \pm 12.19$, which was an average one. In studies by Anbari et al, ${ }^{17}$ Kordi et $\mathrm{al}^{18}$ and Moeini et $a{ }^{19}{ }^{19}$ the participants moderately adhered to self-care behaviors, which was consistent with the results of the present study.

Also, the study by Jordan et al which was cited by Baji et al on self-care behaviors in diabetic patients in the United States showed that patients' self-care status was moderately desirable. ${ }^{20}$ However, the research by Mazloom et $\mathrm{al}^{21}$ and Parham et $\mathrm{al}^{22}$ reported that selfcare levels in the patients were low and undesirable. It 
Table I Self-Care Score Values in Terms of Statistical Variables

\begin{tabular}{|c|c|c|c|c|}
\hline Specifications & Number & Percent & $\begin{array}{l}\text { Self-Care } \\
\text { Score }\end{array}$ & Test Result* \\
\hline $\begin{array}{l}\text { Age } \\
\begin{array}{l}30-40 \\
40-50 \\
50-60 \\
60 \leq\end{array}\end{array}$ & $\begin{array}{l}73 \\
125 \\
172 \\
30\end{array}$ & $\begin{array}{l}18.5 \\
31 \\
43 \\
7.5\end{array}$ & $\begin{array}{l}31.9 \pm 13.1 \\
34.6 \pm 9.7 \\
28.1 \pm 12.7 \\
26.9 \pm 7.4\end{array}$ & $\begin{array}{l}f=0.3 \\
P \text { value }=N S\end{array}$ \\
\hline $\begin{array}{c}\text { GENDER } \\
\text { Female } \\
\text { Man }\end{array}$ & $\begin{array}{l}236 \\
164\end{array}$ & $\begin{array}{l}59 \\
41\end{array}$ & $\begin{array}{l}32.4 \pm 12.8 \\
28.6 \pm 8.6\end{array}$ & $\begin{array}{l}X^{2}=2.4 \\
P \text { value=NS }\end{array}$ \\
\hline $\begin{array}{l}\text { Marital status } \\
\text { Single } \\
\text { Married } \\
\text { Widowed and } \\
\text { divorced and } \\
\text { married }\end{array}$ & $\begin{array}{l}35 \\
278 \\
87\end{array}$ & $\begin{array}{l}8 \\
69 \\
21\end{array}$ & $\begin{array}{l}34.9 \pm 11.8 \\
30.6 \pm 12.2 \\
29.4 \pm 7.9\end{array}$ & $\begin{array}{l}X^{2}=0.4 \\
P \text { value=NS }\end{array}$ \\
\hline $\begin{array}{l}\text { Education } \\
\text { Elementary } \\
\text { Tips } \\
\text { Secondary } \\
\text { Academic }\end{array}$ & $\begin{array}{l}91 \\
94 \\
140 \\
75\end{array}$ & $\begin{array}{l}22 \\
23 \\
35 \\
19\end{array}$ & $\begin{array}{l}28.7 \pm 12.7 \\
31.0 \pm 10.4 \\
30.1 \pm 13.1 \\
32.9 \pm 9.4\end{array}$ & $\begin{array}{l}F=4.3 \\
P \text { value }=0.03\end{array}$ \\
\hline $\begin{array}{l}\text { See your doctor } \\
\text { regularly } \\
\text { Yes } \\
\text { No }\end{array}$ & $\begin{array}{l}274 \\
126\end{array}$ & $\begin{array}{l}68 \\
32\end{array}$ & $\begin{array}{l}37.9 \pm 10.8 \\
31.3 \pm 12.5\end{array}$ & $\begin{array}{l}t=3.8 \\
P \text { value }=0.001\end{array}$ \\
\hline $\begin{array}{l}\text { Family history of } \\
\text { diabetes } \\
\text { Yes } \\
\text { No }\end{array}$ & $\begin{array}{l}293 \\
107\end{array}$ & $\begin{array}{l}73 \\
27\end{array}$ & $\begin{array}{l}35.7 \pm 11.2 \\
30.5 \pm 9.7\end{array}$ & $\begin{array}{l}t=1.2 \\
P \text { value }=N S\end{array}$ \\
\hline $\begin{array}{l}\text { The economic } \\
\text { situation } \\
\text { Poor } \\
\text { medium } \\
\text { Good } \\
\text { Excellent }\end{array}$ & $\begin{array}{l}82 \\
218 \\
78 \\
22\end{array}$ & $\begin{array}{l}21 \\
55 \\
19 \\
5\end{array}$ & $\begin{array}{l}30.6 \pm 13.2 \\
31.4 \pm 12.3 \\
31.7 \pm 9.2 \\
34.7 \pm 10.6\end{array}$ & $\begin{array}{l}X^{2}=3.7 \\
P \text { value }=0.04\end{array}$ \\
\hline $\begin{array}{l}\text { Health } \\
\text { information } \\
\text { resources } \\
\text { Physician and } \\
\text { clinic personnel } \\
\text { Personal study } \\
\text { Other resources }\end{array}$ & $\begin{array}{l}57 \\
38\end{array}$ & $\begin{array}{l}14 \\
10\end{array}$ & $\begin{array}{l}30.7 \pm 12.7 \\
34.5 \pm 9.6 \\
29.2 \pm 11.9\end{array}$ & $\begin{array}{l}\mathrm{X}^{2}=1.9 \\
P \text { value }==N S\end{array}$ \\
\hline
\end{tabular}

Note: *Significance level was less than 0.05 in all subjects.

seems that differences in self-care statuses of patients in the different studies result from differences in various factors such as health literacy levels and/or in self-care educational programs for diabetes patients and/or in knowledge levels and attitudes toward self-care behaviors.

The results of the present study showed that self-care had a direct correlation with education levels. Numerous studies, including those by Shakibzadeh et al, ${ }^{23}$ Karkazloo et al ${ }^{24}$ and Hamedzadeh et $\mathrm{al}^{25}$ reported that there was a significant relationship between education level and self-care ability. Studies have shown that patients with higher education levels have better judgment and decision-making capability for adhering to self-care behaviors.

Moreover, with increased levels of education and awareness in diabetes patients regarding the complications of diabetes and perception of its severity, their attitudes changed, and they decided to take more care of themselves. This, in itself, led them to adhere to the desired behavior. ${ }^{26}$ Based on the results of the study by Baji et al, it can be concluded that increased levels of awareness and education in the studied patients concerning their diseases and self-care facilitated the self-care process. ${ }^{20}$ In other words, high education levels facilitate adherence to selfcare behavior whereas low education levels make this process difficult.

Also, in the study that Baghaei et al conducted in Kashan, illiterate patients adhered to self-care behaviors 8.22 times better than literate patients did. The researchers attributed this to the positive effect of education on the patients and their acquisition of suitable knowledge levels. $^{27}$

The educational process seems to play a decisive role in patients' self-care capability due to its effects on their knowledge level and attitude. ${ }^{27}$ Self-care in diabetes is one of the very important problems in controlling it, and selfcare educational programs can have positive effects on patients' ability in controlling diabetes. ${ }^{28}$ Educating people with diabetes is as important and valuable as medications, exercise, and diet because treatment will be effective when the patient knows the nature of his or her illness well and takes positive steps to cope with it. If we consider diet, exercise, and medicines to be the three main pillars of diabetes, its fourth pillar will certainly be education. ${ }^{29}$

In a study aimed at identifying relationships between health literacy and self-care behaviors, Lai et al noticed that there was a statistically significant relationship between them. Also, the results indicated that there existed a significant direct relationship between communicative and critical health literacy and self-care behaviors in the patients. ${ }^{30}$

Low levels of health literacy also lead to late diagnosis of diseases, ${ }^{31}$ inability concerning self-care skills, ${ }^{32}$ increased use of emergency services and longer hospital stay. ${ }^{11}$

Studies have shown that people have low health literacy levels. Even in developed countries, such as the United States, around 90 million people have limited health literacy 
Table 2 Status Scores of Different Dimensions of Patients' Self-Care

\begin{tabular}{|l|l|l|l|l|l|}
\hline $\begin{array}{l}\text { Dimensions of Self- } \\
\text { Care }\end{array}$ & Average & $\begin{array}{l}\text { Standard } \\
\text { Deviation }\end{array}$ & $\begin{array}{l}\text { Acquired Score } \\
\text { Range }\end{array}$ & $\begin{array}{l}\text { Scored } \\
\text { Range }\end{array}$ & $\begin{array}{l}\text { The Mean Self-Care Score of } \\
100\end{array}$ \\
\hline Healthy diet & 18.19 & 6.39 & $0-28$ & $4-28$ & 32.48 \\
Physical activity & 3.15 & 2.51 & $0-14$ & $1-14$ & 22.5 \\
Blood sugar monitoring & 7.42 & 5.21 & $0-14$ & $5-14$ & 53 \\
Proper use of medicines & 4.76 & 2.16 & $0-7$ & $2-7$ & 17 \\
\hline
\end{tabular}

Table 3 Health Literacy Status of Patients in Different Aspects of Health Literacy

\begin{tabular}{|l|l|l|l|l|l|}
\hline Aspects of Health Literacy & Read & Access & Understanding & Assessment & Decision Making and Behavior \\
\hline Mean \pm SD & $16.2 \pm 3.17$ & $24.7 \pm 4.1$ & $28.4 \pm 3.7$ & $15.8 \pm 2.5$ & $41.8 \pm 6.3$ \\
\hline
\end{tabular}

Table 4 Correlation Coefficient Health Literacy and Self-Care Behavior

\begin{tabular}{|l|l|l|l|l|l|}
\hline \multicolumn{2}{|l|}{ Variables } & \multicolumn{2}{l|}{ Self-Care Behavior } \\
\cline { 3 - 6 } & & $\begin{array}{l}\text { Healthy } \\
\text { Diet }\end{array}$ & $\begin{array}{l}\text { Physical } \\
\text { Activity }\end{array}$ & $\begin{array}{l}\text { Blood Sugar } \\
\text { Monitoring }\end{array}$ & $\begin{array}{l}\text { Proper Use of } \\
\text { Medicines }\end{array}$ \\
\hline Index & $\mathrm{r}$ & $\mathrm{r}$ & $\mathrm{r}$ & $\mathrm{r}$ \\
\hline Health & Read & 0.250 & 0.195 & 0.230 & 0.346 \\
literacy & Access & 0.388 & 0.302 & 0.286 & 0.322 \\
& Understanding & 0.315 & 0.152 & 0.191 & 0.257 \\
& Assessment & 0.150 & 0.265 & 0.310 & 0.146 \\
& Decision making and & 0.190 & 0.217 & 0.386 & 0.262 \\
& behavior & & & & \\
\hline
\end{tabular}

levels. This has led to higher hospitalization rates and increased use of emergency services and costs the economy of health-care system 69 billion dollars per year. ${ }^{33}$

A study in England showed that people with limited health literacy levels had fewer healthy lifestyle behaviors, and the probability of their eating fruits and vegetables at least five times a day improved with increased health literacy levels. ${ }^{34}$ In another study in Jamaica on men 55 years of age and older, only 34 percent prepared the prescribed medications, 7.9\% sought medical care when they were not ill and a significant number did not seek medical care despite being diagnosed with cancer and other chronic diseases. ${ }^{35}$ Another review study reported that people with low literacy levels had 1.5 to three times poorer health outcomes. ${ }^{36}$ In another study in Australia, $45 \%$ of the people with low functional health literacy levels and people with low levels of health literacy adhered more to unhealthy behaviors such as not eating sufficient quantities of fruits and not engaging in adequate physical activities. ${ }^{37}$

Complications of low health literacy levels occur both directly and indirectly. Direct effects include non-compliance with indications or medication errors. Indirect effects are more difficult to measure, but they may include insurancerelated issues, access to health-treatment services and poor health behaviors. ${ }^{38}$ Lower health knowledge levels are associated with less participation in treatment decision-making, fewer cases of expressing health concerns, and poorer communication with physicians. ${ }^{39}$ Various studies have shown that people with low literacy levels are less aware of their disease, are less successful in managing their chronic illness and visit their physicians more frequently. ${ }^{40}$

\section{Limitations and Future Research}

The ethics of the research were sought to be kept confidential. Future research is needed to provide greater insights into patients' self-care behaviors and practices and impact health literacy in all contexts.

\section{Conclusion}

The results showed that health literacy could be one of the factors affecting self-care behaviors of individuals and, 
including it in educational, treatment and caregiving programs was able to improve self-care status in addition to reducing the incidence of complications in patients and improving their quality of life. It is recommended that future researchers in the country evaluate the effects of the health literacy variable on patients' quality of life in a broader range of patients and other areas of the country.

The authors of the article are grateful to the heads and personnel of the health and treatment centers in Mashhad for their support and cooperation and to all the participants in the study who helped us to carry out this project.

\section{Ethics and Consent Statement}

This study is based on a research project approved by the Ethics Committee of Mashhad University of Medical Sciences with the code of ethics IR.MUMS. REC.1398.006. All procedures performed in this study were by the ethical standards of the institutional and/or national research committee and with the 1964 Helsinki declaration and its later amendments or comparable. All project participants were informed of the project goals and have completed a written consent form and they have been assured of confidentiality. This research project is funded by Mashhad University of Medical Sciences.

\section{Acknowledgments}

We would like to express our gratitude and appreciation to all respected professors, clinics, comprehensive health centers and participants in this study, and we wish God the best for each of these dear ones. The authors thank the many colleagues whose vignettes about dilemmas of improving quality shaped this paper, and the anonymous reviewers for their suggestions.

\section{Disclosure}

The authors report no conflicts of interest in this work. The authors alone are responsible for the content and writing of the paper.

\section{References}

1. Noohi E, Khandan M, Mirzazadeh A Effective of electronic education on knowledge attitude and self-care in patient's diabetic type 2 refer to the diabetic center of Kerman University of medical science. 2011.

2. Bidi F, Hassanpour K, Ranjbarzadeh A, Arab KA. Effectiveness of an educational program on knowledge, attitude, self-care, and lifestyle in patients with type II diabetes. 2013.

3. Guariguata L, Whiting DR, Hambleton I, Beagley J, Linnenkamp U, Shaw JE. Global estimates of diabetes prevalence for 2013 and projections for 2035. Diabetes Res Clin Pract. 2014;103(2):137-149. doi:10.1016/j.diabres.2013.11.002
4. Funnell MM, Anderson RM. Empowerment and self-management of diabetes. Clin Diabetes. 2004;22(3):123-127. doi:10.2337/diaclin.22. 3.123

5. Mofid A, Yazdani T, Dulabi H, SA SA, Zandieh S. Lower limb amputation rate in diabetic foot patients: a five-year study. Tehran Univ Med J TUMS Publ. 2008;65(13):38-41.

6. Abazari P, Vanaki Z, Mohammadi E, Amini M. Inadequate investment on the management of diabetes education. J Res Med Sci. 2012;17(8):792-798.

7. Didarloo A, Shojaeizade D, Ardebli H, Niknami S, Hajizadeh E. Factors influencing Women's behavior in diabetes self-care diabetes clinic in Khoy based on rational action theory developed. $J$ Sch Public Health Inst Public Health Res. 2011;9(2):79-92.

8. Rezasefat Balesbaneh A, Mirhaghjou N, Jafsri Asl M, Kohmanaee S, Kazemnejad Leili E, Monfared A. Correlation between self-care and self-efficacy in adolescents with type 1 diabetes. $J$ Holistic Nurs Midwifery. 2014;24(2):18-24.

9. Spenceley SM, Williams BA. Self-care from the perspective of people living with diabetes. Can J Nurs Res. 2006;38(3):124-145.

10. Reisi M, Javadzade SH, Mostafavi F, Sharifirad G, Radjati F, Hasanzade A. Relationship between health literacy, health status, and healthy behaviors among older adults in Isfahan, Iran. $J$ Educ Health Promot. 2012;1(1):31. doi:10.4103/2277-9531.100160

11. Lee SY, Tsai TI, Tsai YW, Kuo KN. Health literacy, health status, and healthcare utilization of Taiwanese adults: results from a national survey. BMC Public Health. 2010;10(1):614. doi:10.1186/14712458-10-614

12. Mahmoodi A, Alavi M, Mousavi N. Investigate the relationship between self-care and with hemoglobin A1C in diabetics. Sci J Hamadan Nurs Midwifery Fac. 2012;20(3):20-25.

13. Shieh C, Halstead JA. Understanding the impact of health literacy on women's health. J Obstet, Gynecol Neonatal Nurs. 2009;38 (5):601-612. doi:10.1111/j.1552-6909.2009.01059.x

14. Lin EH, Katon W, Von Korff M, et al. Relationship of depression and diabetes self-care, medication adherence, and preventive care. Diabetes Care. 2004;27(9):2154-2160. doi:10.2337/diacare.27.9.2154

15. Hatamloo M, Babapour J, Poorsharifi H. Health locus of control and causal trends in predicting self-care roles of people with diabetes. J Tabriz Uni Psychiatry. 2010;5(19):32-53.

16. Montazeri A, Tavousi M, Rakhshani F, et al. Health Literacy for Iranian Adults (HELIA): development and psychometric properties. 2014.

17. Anbari K, Ghanadi K, Kaviani M, Montazeri R. The self care and its related factors in diabetic patients of khorramabad city. Yafteh. 2012;14(4):49-57.

18. Kordi M, Banaei M, Asgharipour N, Mazloum SR, Akhlaghi F. Prediction of self-care behaviors of Women with gestational diabetes based on belief of person in own ability (self-efficacy). Iran J Obstet, Gynecol Infertil. 2016;19(13):6-17.

19. Moeini B, Teimouri P, Haji Masoudi S, et al. Analyse of self-care behaviours and its related factors among diabetic patients. Qom Univ Med Sci J. 2016;10(4):48-57.

20. Baji Z, Zamani Alavijeh F, Nouhjah S, Haghighizadeh M. Self-care behaviors and related factors in women with type 2 diabetes. Iran J Endocrinol Metabol. 2015;16(6):393-401.

21. Mazlom SR, Firooz M, Hoseini SJ, Hasanzadeh F, Kimiaie SA. Selfcare of patient with diabetes type II. 2016.

22. Parham M, Rasooli A, Safaeipour R, Mohebi S Assessment of effects of self-caring on diabetic patients in Qom diabetes association 2013. 2014.

23. Shakibazadeh E, Larigani B, SHojaeizadeh D, Frouzanfar M, KarimiShahanjerini A. The relationship between efficacy and perceived barriers to self-care functioning in patients with type 2 diabetes. J Hayat. 2009;15(4):69-78.

24. Karkazloo NV, Daryasari GA, Farahani B, Mohammadnezhad E, Sajjadi A. The study of self-care agency in patients with diabetes (Ardabil). Mod Care J. 2011;8(4). 
25. Hamadzadeh S, Ezatti Z, Abedsaeidi Z, Nasiri N. Coping styles and self-care behaviors among diabetic patients. Iran J Nurs. 2013;25 (80):24-33.

26. Barati M. Predicting factors related to self-care behaviors among type 2 diabetic patients based on health belief model. $J$ Torbat Heydariyeh Univ Med Sci. 2014;1(4):16-25.

27. Baghaei P, Zandi M, Vares Z, Masoudi Alavi N, Adib-Hajbaghery M. Self care situation in diabetic patients referring to Kashan Diabetes Center, in 2005. KAUMS J (Feyz). 2008;12(1):88-93.

28. Shahbaz A, Nejad Rahim R, Hemmati Maslak Pak M, Khalkhali HR. The effect of implementing Orem's self-care program on self-care behaviors in patients with diabetic foot ulcer. J Urmia Nurs Midwifery Faculty. 2016;14(2):108-117.

29. Parizad N, HEMMATI MM, Khalkhali H. Promoting self-care in patients with type 2 diabetes: tele-education. 2013.

30. Lai AY, Ishikawa H, Kiuchi T, Mooppil N, Griva K. Communicative and critical health literacy, and self-management behaviors in end-stage renal disease patients with diabetes on hemodialysis. Patient Educ Couns. 2013;91(2):221-227. doi:10.1016/j.pec.2012.12.018

31. Bennett CL, Ferreira MR, Davis TC, et al. Relation between literacy, race, and stage of presentation among low-income patients with prostate cancer. J Clin Oncol. 1998;16(9):3101-3104. doi:10.1200/ JCO.1998.16.9.3101

32. Schillinger D, Grumbach K, Piette J, et al. Association of health literacy with diabetes outcomes. JAMA. 2002;288(4):475-482. doi:10.1001/jama.288.4.475

33. Tol A, Pourreza A, Foroshani R, Tavassoli E. Assessing the effect of educational program based on small group on promoting knowledge and health literacy among women with type 2 diabetes referring to selected hospitals affiliated to Tehran University of Medical Sciences. Razi J Med Sci. 2013;19(104):10-19.
34. von Wagner C, Knight K, Steptoe A, Wardle J. Functional health literacy and health-promoting behaviour in a national sample of British adults. J Epidemiol Community Health. 2007;61 (12):1086-1090. doi:10.1136/jech.2006.053967

35. Bourne PA, Morris C, Charles CA, Eldemire-Shearer D, KerrCampbell MD, Crawford TV. Health literacy and health seeking behavior among older men in a middle-income nation. Patient Relat Outcome Meas. 2010;1:39-49. doi:10.2147/PROM.S11141

36. DeWalt DA, Berkman ND, Sheridan S, Lohr KN, Pignone MP. Literacy and health outcomes. J Gen Intern Med. 2004;19 (12):1228-1239. doi:10.1111/j.1525-1497.2004.40153.x

37. Adams RJ, Piantadosi C, Ettridge K, et al. Functional health literacy mediates the relationship between socio-economic status, perceptions and lifestyle behaviors related to cancer risk in an Australian population. Patient Educ Couns. 2013;91(2):206-212. doi:10.1016/ j.pec.2012.12.001

38. Karimi S, Keyvanara M, Hosseini M, Jafarian M, Khorasani E. Health literacy, health status, health services utilization and their relationships in adults in Isfahan. Health Inf Manage. 2014;10 (6):862-875.

39. Peerson A, Saunders M. Health literacy revisited: what do we mean and why does it matter? Health Promot Int. 2009;24(3):285-296. doi:10.1093/heapro/dap014

40. Gazmararian JA, Williams MV, Peel J, Baker DW. Health literacy and knowledge of chronic disease. Patient Educ Couns. 2003;51 (3):267-275. doi:10.1016/S0738-3991(02)00239-2
Patient Related Outcome Measures

\section{Publish your work in this journal}

Patient Related Outcome Measures is an international, peer-reviewed, open access journal focusing on treatment outcomes specifically relevant to patients. All aspects of patient care are addressed within the journal and practitioners from all disciplines are invited to submit their work as well as healthcare researchers and patient support groups.
The manuscript management system is completely online and includes a very quick and fair peer-review system. Visit http://www. dovepress.com/testimonials.php to read real quotes from published authors. 